\title{
Expression, purification, and characterization of thermolabile hemolysin (TLH) from Vibrio alginolyticus
}

\author{
Airong Jia ${ }^{1}$, Norman Y. S. Woo ${ }^{2}$, Xiao-Hua Zhang ${ }^{1, *}$ \\ ${ }^{1}$ Department of Marine Biology, Ocean University of China, Qingdao, PR China \\ ${ }^{2}$ Biology Department, the Chinese University of Hong Kong, Hong Kong, SAR
}

\begin{abstract}
Hemolysin is a putative pathogenicity factor in many bacterial pathogens. In this study, a DNA fragment containing the open reading frame (1254 bp) of the thermolabile hemolysin gene (tlh) from Vibrio alginolyticus V05 was amplified and cloned into the expression plasmid pET-24d(+). The deduced amino acid sequence of the thermolabile hemolysin (TLH) shared 94 and $83 \%$ identity with the lecithin-dependent hemolysin (LDH)/TLH of $V$. parahaemolyticus and $V$. harveyi thermolabile hemolysin ( $\mathrm{VHH})$, respectively. The sequence analysis also indicated that it contained a GDSL lipase domain like VHH. The recombinant protein with a predicted molecular mass of 47.2 kDa was expressed in the Escherichia coli strain BL21 (DE3) as a His-tag fused protein. TLH purified by the nickel-nitrilotriacetic acid (Ni-NTA) His-Bind Resin method showed phospholipase activity on an egg yolk emulsion plate and hemolytic activity against flounder erythrocytes with a specific activity of 18 hemolytic units $\mu^{-1}$. The addition of divalent cations at different concentrations decreased hemolytic activity of the purified TLH, but monavalent cations did not affect hemolytic activity. The hemolytic activity of TLH was also markedly inhibited by protein modification reagents, i.e. B-mercaptoethanol, phenylmethylsulfonyl fluoride, and 5,5'-dithio-bis(2-nitrobenzoic acid). Moreover, TLH was toxic to zebrafish when injected intraperitoneally, with a median lethal dose $\left(\mathrm{LD}_{50}\right)$ of $0.8 \mu \mathrm{g}$ protein $\mathrm{g}^{-1}$ fish. This work shows that TLH could potentially be developed as a vaccine and used as a diagnostic tool for vibriosis.
\end{abstract}

KEY WORDS: Vibrio alginolyticus $\cdot$ Hemolysin $•$ Expression $•$ Purification $\cdot$ Pathogenicity

Resale or republication not permitted without written consent of the publisher

\section{INTRODUCTION}

Vibriosis is a systemic disease of marine fish that is characterized by general bacterial septicemia, hemorrhaging, and skin lesions. The causative agents of vibriosis are a group of bacterial pathogens belonging to the genus Vibrio (Egidius 1987, Zhang \& Austin 2005, Jayaprakash et al. 2006). V. alginolyticus is a gramnegative, estuarine bacterial species and is the closest relative of $V$. parahaemolyticus (González-Escalona et al. 2006, Cai et al. 2007). V. alginolyticus has been described as an important pathogen, and is responsible for the ulcer disease of gilthead sea bream Sparus aurata, turbot Scophthalmus maximus, crimson snapper Lutjanus erythopterus, sea mullet Mugil cephalus, and giant freshwater prawn Macrobrachium rosenbergii (Kim et al. 2000, Selvin \& Lipton 2003, Jaya- prakash et al. 2006, Cai et al. 2007). Previous studies have shown that $V$. alginolyticus is a major infective pathogen for silver sea bream Sparus sarba, an edible fish of major economic value to Hong Kong ( $\mathrm{Li}$ et al. 2003). Enzymatic characterization of the isolated extracellular products (ECP) of pathogenic $V$. alginolyticus demonstrated the presence of hemolysin that was specific only to fish blood (Li et al. 2003).

Hemolysin, an exotoxin that lyses erythrocyte membranes with the liberation of hemoglobin, is arguably the most widely distributed toxin among pathogenic Vibrio spp. and exerts various roles in the infection process (Shinoda 1999). There are 5 representative hemolysin families in Vibrio spp., including the thermostable direct hemolysin (TDH) family, the HlyA (or E1 Tor hemolysin) family, the thermolabile hemolysin (TLH) family, the thermostable hemolysin $(\delta-\mathrm{VPH})$ family, and a 
novel hemolysis gene (HLX) family (Zhang \& Austin 2005). TDH and HlyA have been studied extensively and are closely associated with virulence (Zhang \& Austin 2005, Cai et al. 2007). However, the role of some other hemolysins, e.g. TLH, $\delta$-VPH, and HLX, is unclear and will need to be determined by further research (Singh et al. 2009), although previous studies have indicated that TLH is widespread among Vibrio (Wang et al. 2007, Parvathi et al. 2009). In V. alginolyticus, the hemolysins of TDH and thermostable direct hemolysinrelated hemolysin (TRH) have been well studied (González-Escalona et al. 2006, Cai et al. 2007), but the TLH hemolysin of this bacterium has not been characterized yet.

In the present study, we cloned and expressed the tlh gene from Vibrio alginolyticus in Escherichia coli, purified the recombinant TLH, and investigated some of its biological and biochemical characteristics.

\section{MATERIALS AND METHODS}

Bacterial strains, plasmids, and test animals. Vibrio alginolyticus V05 and V. harveyi V01 that had previously been isolated from infected sea bream cultured in Tolo Harbour, Hong Kong, were supplied by the Biology Department, the Chinese University of Hong Kong. V. alginolyticus VIB 283, and V. harveyi VIB 645 and VIB 647 were obtained from the School of Life Sciences, Heriot-Watt University, UK. These strains were cultured at $28^{\circ} \mathrm{C}$ on marine $2216 \mathrm{E}$ agar plates. The expression vector pET-24d (+) (with a C-terminal HisTag) and the E. coli strain BL21 (DE3), used for overexpression of $\mathrm{TLH}$, were purchased from Novagen. Luria-Bertani (LB) medium was used for the routine culturing of E. coli at $37^{\circ} \mathrm{C}$. The E. coli transformants with recombinant plasmid were maintained on LB agar containing kanamycin (LB-Kan, $50 \mu \mathrm{g} \mathrm{ml}^{-1}$ ).

Zebrafish Danio rerio were purchased from the market in Qingdao, and the fish were maintained in an aquarium at 26 to $30^{\circ} \mathrm{C}$ during the experiments involving lethality tests of TLH.

DNA extraction. Total bacterial genomic DNA from Vibrio alginolyticus and $V$. harveyi strains were prepared using the TIANamp Bacteria DNA Kit (Tiangen) according to the manufacturer's instructions.

Construction of an overexpression vector. The tlh gene was obtained by PCR amplification using the DNA of Vibrio alginolyticus V05 as template. According to the $1 d h / t l h$ hemolysin gene (1254 bp) of the whole genome shotgun sequence from $V$. alginolyticus 12G01 (GenBank accession no. NZ_AAPS01000004), a specific primer set (TLHF and TLHR) was designed. The forward primer (TLHF: 5'-CCG GAA TTC ATG AAA AAA ACA ATC ACA CT-3') begins from the initiation codon and adds an EcoRI site at the 5' end of the gene, and the reverse primer (TLHR: $5^{\prime}$-CGC TCG AGA AAG CGA AAC TCT TCT AAG T-3') ends before the stop codon, and adds an XhoI site. The primer set was tested in PCR with DNA templates prepared from different strains of $V$. alginolyticus (V05, VIB283) and V. harveyi (V01, VIB645, VIB647), using 50 ng DNA template, $1 \times$ PCR buffer, $1.5 \mathrm{mM}$ of $\mathrm{MgCl}_{2}, 200 \mu \mathrm{M}$ of each dNTP, $0.5 \mu \mathrm{M}$ concentration of each primer, and $0.5 \mathrm{U}$ of Taq DNA polymerase (Fermentas) in a total volume of $20 \mu$. The PCR conditions consisted of an initial denaturation step at $94^{\circ} \mathrm{C}$ for $5 \mathrm{~min}$, followed by 30 cycles at $94^{\circ} \mathrm{C}$ for $1 \mathrm{~min}, 50^{\circ} \mathrm{C}$ for $40 \mathrm{~s}$, and $72^{\circ} \mathrm{C}$ for $1.5 \mathrm{~min}$, and a final extension of $10 \mathrm{~min}$ at $72^{\circ} \mathrm{C}$. The PCR product of $V$. alginolyticus V05 (1268 bp) was excised and inserted into the EcoRI/XhoI-cut expression vector pET-24d (+). The ligated plasmid was transformed into E. coli BL21 (DE3) for expression of the full-length th gene. The sequence of the cloned gene in the pET-24d (+) vector was confirmed by DNA sequencing (Biosung).

Expression and purification of TLH from transformed $\boldsymbol{E}$. coli. The expression of TLH was performed as described by Zhong et al. (2006). In brief, a single colony of E. coli BL21 (DE3) transformed with pET-24d $(+) / t$ lh was inoculated into $5 \mathrm{ml}$ of LB-Kan broth and incubated at $37^{\circ} \mathrm{C}$ for $12 \mathrm{~h}$ with shaking at $180 \mathrm{rpm}$. This culture was inoculated into $495 \mathrm{ml}$ of the same medium and allowed to grow for another $2.5 \mathrm{~h}$, until the optical density $\left(\mathrm{OD}_{600}\right)$ value reached 0.6. Expression of TLH was induced by adding isopropyl $\beta$-D-1thiogalactopyranoside (IPTG) to a final concentration of $1 \mathrm{mM}$, with additional incubation at $25^{\circ} \mathrm{C}$ for $6 \mathrm{~h}$.

To purify the TLH from the bacterial cells, the induced cells were harvested by centrifugation at $4000 \times$ $g$ for $20 \mathrm{~min}$ at $4^{\circ} \mathrm{C}$, and the pellet was resuspended in $50 \mathrm{ml}$ nickel-nitrilotriacetic acid (Ni-NTA) bind buffer containing $10 \mathrm{mM}$ imidazole, and then lysed by ultrasonication and centrifuged at $10000 \times g$ for $30 \mathrm{~min}$ at $4{ }^{\circ} \mathrm{C}$. The supernatant was checked for expression and processed for purification. Purification of poly Histagged TLH was performed using Ni-NTA His-Bind Resin according to the manufacturer's instructions (Novagen). The TLH was purified by performing a 2step elution with $50 \mathrm{mM}$ imidazole after the $20 \mathrm{mM}$ imidazole wash, followed by $250 \mathrm{mM}$ imidazole elution. The expression and purity of TLH were analyzed by sodium dodecyl sulphate polyacrylamide gel electrophoresis (SDS-PAGE), and the concentration of TLH was determined by the dye-binding method of Bradford (1976). For signal sequence prediction, the SignalP program (www.cbs.dtu.dk/services/SignalP-3.0) was used (Nielsen et al. 1999).

Assay of hemolytic activity and phospholipase activity. Hemolytic activity against flounder Paralichthys olivaceus erythrocytes was measured by a 
previously published procedure (Zhang et al. 2001). In brief, the purified TLH (100 hemolytic units, HU) was added to an Oxford cup (5 mm diameter), which was placed on the plate and incubated at $37^{\circ} \mathrm{C}$ for $8 \mathrm{~h}$. The hemolytic activity against sheep erythrocytes was measured as above except that it was performed on Columbia blood agar base with sheep erythrocytes (HopeBio), supplied with TLH of 100, 200, 500, 1000, 3000,4000 , and $6000 \mathrm{HU}$, which were reacted for $10 \mathrm{~h}$ at $37^{\circ} \mathrm{C}$. A hemolytic titer was carried out in a 96-well microtiter plate (Costar), in which $100 \mu \mathrm{TLH}$ were diluted 2-fold in $20 \mathrm{mM}$ Tris-buffered saline (TBS, $\mathrm{pH} 7.5$ ) and mixed with equal volumes of the $2 \%(\mathrm{v} / \mathrm{v})$ erythrocyte suspension. TBS was used as negative control. The plate was incubated at $37^{\circ} \mathrm{C}$ for $2 \mathrm{~h}$, and the hemolytic titer was recorded as the reciprocal of the dilution that gave an end product of $50 \%$ hemolysis, and that reciprocal of the dilution was defined as $1 \mathrm{HU}$. All the hemolytic activity experiments were performed in triplicate.

Phospholipase activity was detected as previously described (Montero \& Austin 1999, Zhong et al. 2006). A $20 \mu$ aliquot of TLH (100 HU) was added to Oxford cups, which were placed on $1 \%$ (v/v) egg yolk emulsion and incubated at $28^{\circ} \mathrm{C}$ for $24 \mathrm{~h}$. The lipase domain in the deduced amino acid sequence was analyzed via Pfam (Wellcome Trust Sanger Institute: http://pfam. sanger.ac.uk/).

Effects of metallic cations on hemolytic activity. The effect of cations on hemolysis was determined by addition of various concentrations of metallic cations $\left(\mathrm{Na}^{+}\right.$, $\mathrm{K}^{+}, \mathrm{Mg}^{2+}, \mathrm{Ca}^{2+}, \mathrm{Mn}^{2+}, \mathrm{Co}^{2+}, \mathrm{Ni}^{2+}, \mathrm{Cu}^{2+}, \mathrm{Zn}^{2+}$, and $\left.\mathrm{Ba}^{2+}\right)$ as the chloride forms in $20 \mathrm{mM}$ TBS (pH 7.5; Jeon et al. 2009). The metallic cation solution was added to TLH (100 HU), and the mixture was incubated at $30^{\circ} \mathrm{C}$ for 30 min and immediately subjected to the hemolytic assay. The hemolytic activity experiment was performed in a 96-well microtiter plate as described above. In brief, the mixtures $(100 \mu \mathrm{l})$ were double diluted and mixed with equal volumes of the $2 \%(\mathrm{v} / \mathrm{v})$ erythrocyte suspension. The residual hemolytic activity was recorded. The mixtures of each metallic cation and erythrocyte were used as controls in doubling dilutions.

Effects of modification reagents on hemolytic activity. To determine functional groups in the TLH structure, TLH (100 HU) was mixed with various concentrations $(0,0.1,1,10 \mathrm{mM})$ of chemical modification reagents and incubated at $30^{\circ} \mathrm{C}$ for $30 \mathrm{~min}$. 1-ethyl-3(3-dimethylaminopropyl) carbodiimide hydrochloride (EDC. $\mathrm{HCl}), 2,4,6$-trinitrobenzene sulfonate (TNBS), diethyl pyrocarbonate (DEPC), $\beta$-mercaptoethanol $(\beta M E)$, phenylmethylsulfonyl fluoride (PMSF), and 5,5'-dithiobis(2-nitrobenzoic acid) (DTNB) were used to modify the carboxy group in glutamic acid/aspartic acid, amino group, imidazolyl in histidine, disulfide bond, hydroxy group in serine, and hydrosulfide group in cysteine, respectively (Kazan \& Erarslan 2001, Sultan et al. 2004). The hemolytic activity of the mixtures was detected as described.

Fish pathogenicity. Zebrafish from quarantined stocks recognized as disease-free (Austin \& Austin 1989) were used as models to assess pathogenicity as described below (Zhong et al. 2006). Groups of 10 fish (average weight: $0.447 \mathrm{~g}$ ) were infected by intraperitoneal injection with $25 \mu \mathrm{l}$ volumes of 2 -fold dilutions of TLH preparations. Sterile TBS was also injected as parallel controls. Mortality of fish was recorded for $7 \mathrm{~d}$ after injection. The median lethal dose $\left(\mathrm{LD}_{50}\right)$ was calculated using the probit method described by Wardlaw (1985).

\section{RESULTS}

\section{Construction of an overexpression vector}

The full-length sequence of th revealed an open reading frame (ORF) of $1254 \mathrm{bp}$ that encodes a 417 amino acid polypeptide with a predicted molecular mass of $47.2 \mathrm{kDa}$ and an isoelectric point (pI) of 5.08 (GenBank accession no. GQ300939). The deduced amino acids of the TLH showed 94 and $83 \%$ homology to the lecithin-dependent hemolysin (LDH)/TLH of Vibrio parahaemolyticus (GenBank accession no. EDM60410) and $V$. harveyi thermolabile hemolysin (VHH; GenBank accession no. AF293430), respectively. The PCR primers TLHF and TLHR amplified a $\sim 1.3 \mathrm{~kb}$ DNA fragment containing the full-length th gene from $V$. alginolyticus strains, but not in a PCR using DNA templates from strains of $V$. harveyi (Fig. 1). Amplified product from V05 (Fig. 1, Lane 1)

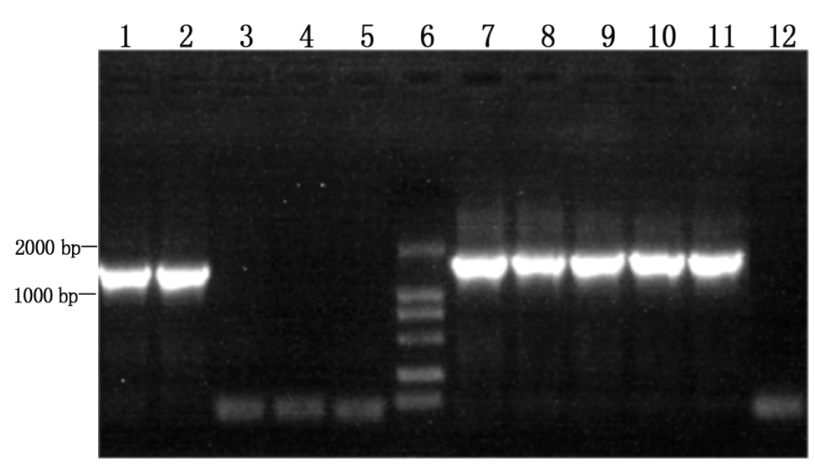

Fig. 1. Results of the PCR using different DNA as templates. Lanes 1-5: amplification of the hemolysin gene using primers TLHF and TLHR, the PCR template from Vibrio alginolyticus V05, V. alginolyticus VIB 283, V. harveyi VIB645, V. harveyi VIB647, and $V$. harveyi V01, respectively; Lane 6: marker DL2000; Lanes 7-11: amplification of the 16srDNA as positive control, using the above strains in the same order; Lane 12: negative control (no template) 
was cloned into E. coli BL21 (DE3) using the pET-24d $(+)$ vector. A stop codon was not incorporated in the reverse primer so that a histidine tag would be expressed at the C-terminus of TLH to simplify subsequent purification procedures.

\section{Purification of TLH from transformed E. coli}

TLH was found to exist in both the culture supernatant and bacterial cells, but the yield of TLH from the culture supernatant was lower than that obtained from the bacterial cells. Intracellular TLH was purified by Ni-NTA His-Bind Resin, and $5 \mathrm{ml}$ protein (2.199 mg $\mathrm{ml}^{-1}$ ) were obtained. Based on the analysis of SignalP, a leader peptide of 20 amino acids should be removed from the fused TLH (48.2 kDa) containing poly His-tag to form a mature peptide with a predicted molecular mass of $46.2 \mathrm{kDa}$. SDS-PAGE analysis of the purified TLH from transformed cells revealed a single band with an estimated molecular weight of $\sim 45 \mathrm{kDa}$ (Fig. 2).

\section{Hemolytic and phospholipase activities}

The culture of induced E. coli with recombinant plasmid displayed hemolytic and phospholipase activities compared to non-induced transformed cells (Figs. 3 \& 4). The appearance of a lytic zone on blood agar and the presence of an opalescent zone around the well on egg yolk emulsion plates were recorded as evidence of positivity. The sheep erythrocytes were not very sensi-

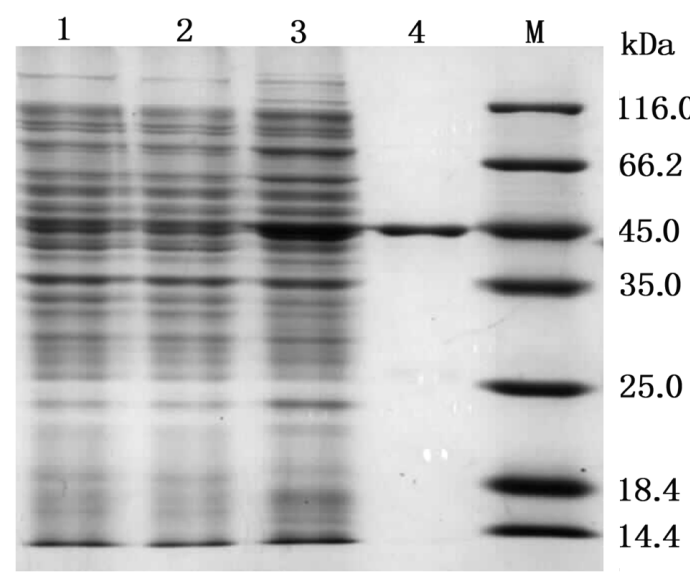

Fig. 2. Expression of $t$ lh in the pET-24d (+) vector using Escherichia coli BL21 (DE3) as the host. Lane 1: negative control without the tlh fragment; Lane 2: uninduced cell pellet fraction; Lane 3: induced cell pellet fraction; Lane 4: purified Vibrio alginolyticus thermolabile hemolysin from transformed E. coli cells; Lane M: molecular marker
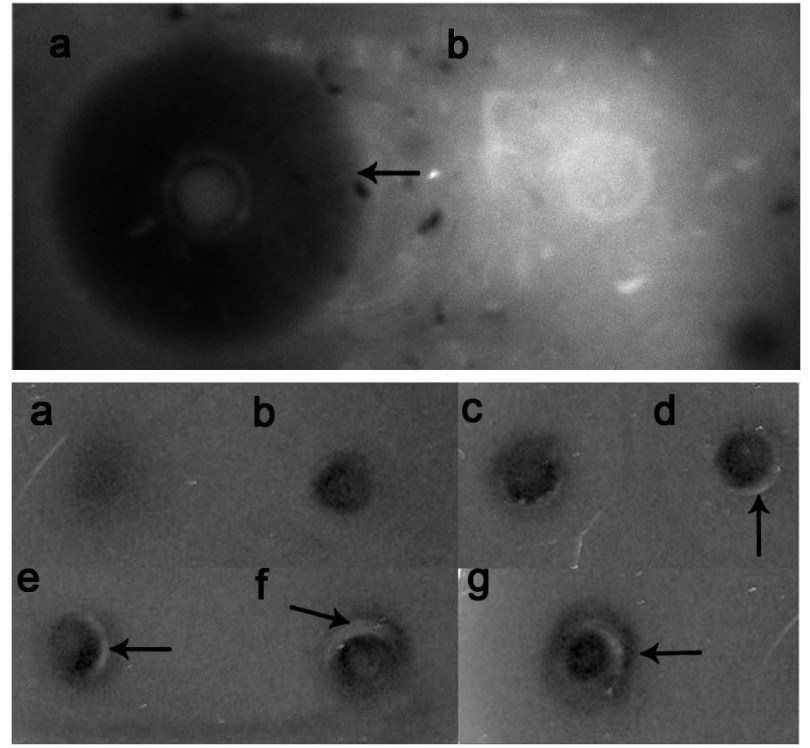

Fig. 3. Hemolytic activity of Vibrio alginolyticus thermolabile hemolysin (TLH) on blood agar plate. Top: TLH on a flounder blood agar plate. (a) purified TLH from transformed Escherichia coli cells; (b) whole cell lysates of uninduced sample. Bottom: TLH on a sheep blood agar plate. Purified TLH of 100 , 200, 500, 1000, 3000, 4000, and 6000 hemolytic units (HU) was added to Oxford cups from (a) to (g), respectively. Arrows show the sites of hemolysis

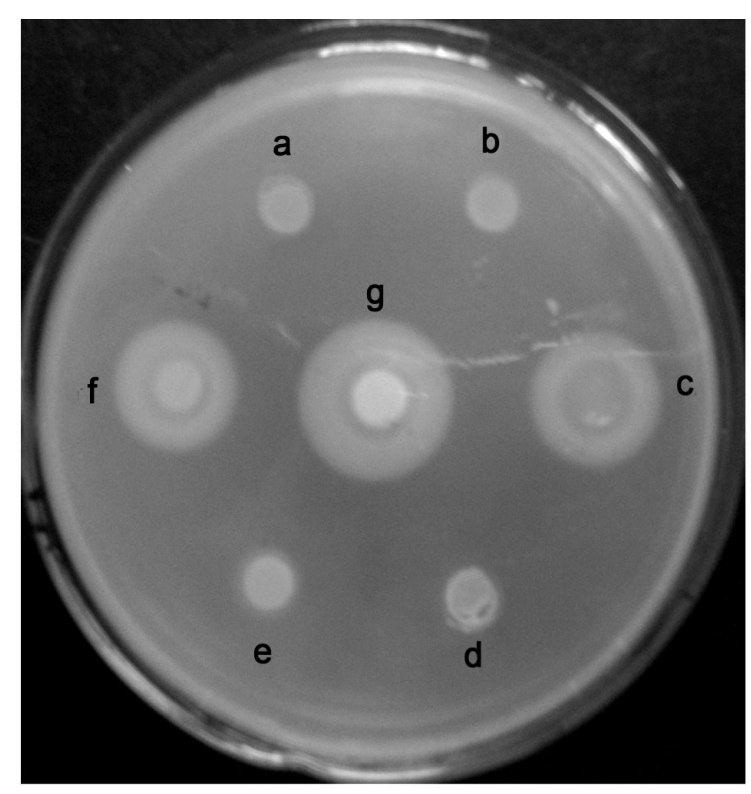

Fig. 4. Phospholipase activity of Escherichia coli BL21 (DE3) containing recombinant plasmid and purified thermolabile hemolysin (TLH) was analyzed on an egg yolk emulsion plate. Culture supernatant of the (a) negative control without th, (b) uninduced sample, (c) induced sample. Whole cell lysates of the (d) negative control without tlh, (e) uninduced sample, (f) induced sample. (g) Purified TLH from transformed E. coli cells 
tive to TLH hemolysin, and the TLH could display obvious hemolytic activity up to $6000 \mathrm{HU}$ (compared to $100 \mathrm{HU}$ against flounder erythrocytes). The specific

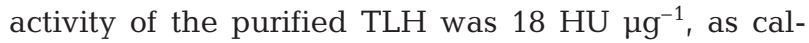
culated using a hemolytic titer. Based on the Pfam analysis, the predicted protein had one GDSL-like lipase/acylhydrolase domain from 146 to 405 amino acids.

\section{Effects of metallic cations on hemolytic activity}

As shown in Table $1, \mathrm{Na}^{+}$and $\mathrm{K}^{+}$did not affect hemolytic activity at $1 \mathrm{mM}$ and $25 \mathrm{mM}$ concentrations. At $1 \mathrm{mM}$ concentration, $\mathrm{Mg}^{2+}, \mathrm{Ca}^{2+}, \mathrm{Mn}^{2+}$, and $\mathrm{Ba}^{2+}$ decreased the activity to $25 \%$, and $\mathrm{Co}^{2+}, \mathrm{Ni}^{2+}$, and $\mathrm{Zn}^{2+}$ decreased the activity by $50 \%$. However, addition of $\mathrm{Cu}^{2+}$ at $1 \mathrm{mM}$ caused the erythrocytes to rupture. The addition of all divalent cations decreased the activity by $50 \%$ at $0.1 \mathrm{mM}$. When the concentration of $\mathrm{Zn}^{2+}$ was increased to $25 \mathrm{mM}$, the hemolytic activity was decreased to $25 \%$. No metallic cations, except $\mathrm{Cu}^{2+}$ at $1 \mathrm{mM}$, caused the destruction of erythrocytes by themselves.

\section{Effects of modification reagents on hemolytic activity}

As shown in Table 2, the effect of 6 chemical modification reagents on hemolytic activity was detected at 0 , $0.1,1$, and $10 \mathrm{mM}$. TNBS and DEPC decreased the activity by $50 \%$ at $0.1,1$, and $10 \mathrm{mM}$ concentrations. The other 4 reagents also decreased the activity by $50 \%$ at $0.1 \mathrm{mM}$, and $\mathrm{EDC} \cdot \mathrm{HCl}$ at $1 \mathrm{mM}$ caused the hemolytic activity to remain at $50 \%$. When the concentration of $\beta \mathrm{ME}$, PMSF, and DTNB was increased to

Table 1. Effects of metallic cations on the hemolytic activity of Vibrio alginolyticus thermolabile hemolysin. Metallic cations were dissolved in Tris-buffered saline. ND: not determined

\begin{tabular}{|lccc|}
\hline \multirow{2}{*}{$\begin{array}{l}\text { Metallic } \\
\text { cation }\end{array}$} & \multicolumn{3}{c|}{ Relative hemolytic activity $(\%)$} \\
& $0.1 \mathrm{mM}$ & $1 \mathrm{mM}$ & $25 \mathrm{mM}$ \\
\hline $\mathrm{Na}^{+}$ & $\mathrm{ND}$ & 100 & 100 \\
$\mathrm{~K}^{+}$ & $\mathrm{ND}$ & 100 & 100 \\
$\mathrm{Mg}^{2+}$ & 50 & 25 & $\mathrm{ND}$ \\
$\mathrm{Ca}^{2+}$ & 50 & 25 & $\mathrm{ND}$ \\
$\mathrm{Mn}^{2+}$ & 50 & 25 & $\mathrm{ND}$ \\
$\mathrm{Co}^{2+}$ & 50 & 50 & $\mathrm{ND}$ \\
$\mathrm{Ni}^{2+}$ & 50 & 50 & $\mathrm{ND}$ \\
$\mathrm{Cu}^{2+}$ & 50 & $\mathrm{ND}$ & $\mathrm{ND}$ \\
$\mathrm{Zn}^{2+}$ & 50 & 50 & 25 \\
$\mathrm{Ba}^{2+}$ & 50 & 25 & $\mathrm{ND}$ \\
None & 100 & 100 & 100 \\
& & & \\
\hline
\end{tabular}

Table 2. Effect of chemical modification reagents on the hemolytic activity of Vibrio alginolyticus thermolabile hemolysin. EDC.HCl: 1-ethyl-3-(3-dimethylaminopropyl) carbodiimide hydrochloride; TNBS: 2,4,6-trinitrobenzene sulfonate; DEPC: diethyl pyrocarbonate; $\beta \mathrm{ME}$ : $\beta$-mercaptoethanol; PMSF: phenylmethylsulfonyl fluoride; DTNB: 5,5'-dithiobis (2-nitrobenzoic acid)

\begin{tabular}{|lccc|}
\hline \multirow{2}{*}{$\begin{array}{l}\text { Modification } \\
\text { reagent }\end{array}$} & \multicolumn{3}{c|}{ Relative hemolytic activity $(\%)$} \\
& $0.1 \mathrm{mM}$ & $1 \mathrm{mM}$ & $10 \mathrm{mM}$ \\
\hline EDC.HCl & 50 & 50 & 25 \\
TNBS & 50 & 50 & 50 \\
DEPC & 50 & 50 & 50 \\
$\beta$ ME & 50 & 25 & 12.5 \\
PMSF & 50 & 25 & 12.5 \\
DTNB & 50 & 12.5 & 6.25 \\
None & 100 & 100 & 100 \\
\hline
\end{tabular}

$1 \mathrm{mM}$, the hemolytic activity was decreased to 25,25 , and $12.5 \%$, respectively. There was continued decline in hemolytic activity, with losses of $75,87.5,87.5$, and $93.75 \%$ of activity after the addition of $\mathrm{EDC} \cdot \mathrm{HCl}, \beta \mathrm{ME}$, PMSF, and DTNB at $10 \mathrm{mM}$ concentration, respectively. Moreover, the modification reagents did not rupture the erythrocytes by themselves at concentrations of $0.1,1$, and $10 \mathrm{mM}$.

\section{Pathogenicity of TLH to zebrafish}

Mortalities among zebrafish occurred between 1 and $120 \mathrm{~h}$ after injection of TLH. Most infected fish exhibited hemorrhaging in the peritoneal cavity, and signs of hemorrhage and necrosis at the site of the injection. The 32-fold diluted TLH at a concentration of $0.069 \mu \mathrm{g}$ $\mu^{-1}$ killed all fish when $25 \mu \mathrm{l}$ volumes were injected. In comparison, the 64-, 128-, and 256-fold diluted protein killed 80,70 , and $10 \%$ of the fish, respectively (Table 3). Thus, the $\mathrm{LD}_{50}$ value of TLH to zebrafish was established as $0.8 \mu \mathrm{g}$ protein $\mathrm{g}^{-1}$ fish.

Table 3. Pathogenicity of thermolabile hemolysin (TLH) to zebrafish Danio rerio. Groups of 10 fish (average weight: $0.447 \mathrm{~g}$ ) were injected with $25 \mu \mathrm{l}$ volumes of 2 -fold dilutions of TLH preparations. Controls were injected with $25 \mu \mathrm{l}$ volumes of Tris-buffered saline

\begin{tabular}{|lcc|}
\hline $\begin{array}{l}\text { Dose } \\
\left(\mu \mathrm{g} \text { protein } \mathrm{g}^{-1} \text { fish }\right)\end{array}$ & $\begin{array}{c}\text { Total mortality } \\
(\mathrm{n}=10)\end{array}$ & $\begin{array}{c}\text { Time to death } \\
(\mathrm{h})\end{array}$ \\
\hline 0 & 0 & - \\
0.231 & 0 & - \\
0.463 & 1 & 120 \\
0.925 & 7 & $4-104$ \\
1.850 & 8 & $2-96$ \\
3.700 & 10 & $1-9$ \\
\hline
\end{tabular}




\section{DISCUSSION}

Our understanding of the role of hemolysin in the pathogenesis of vibriosis has largely been based on the results of previous studies on purification, characterization, mutation, and pathogenicity of VHH (Zhang et al. 2001, Zhong et al. 2006, Sun et al. 2007). In this study, we cloned, overexpressed, and purified the thh gene from Vibrio alginolyticus. The predicted molecular mass of fused TLH was $48.2 \mathrm{kDa}$, which was 2 to $3 \mathrm{kDa}$ larger than that determined by SDS-PAGE. The gel mobility of proteins often reflects their physicochemical properties and posttranslational modifications beyond their molecular masses, which may cause inconsistencies between the mobility and molecular mass (Shirai et al. 2008). The other reason for the difference in size may be due to splicing of the signal peptide of TLH. Zhong et al. (2006) demonstrated that $20 \mathrm{~N}$-terminal amino acids were deleted from the recombinated $\mathrm{VHH}$ when secreted into the medium. Another study also found that $V$. fluvialis hemolysin was secreted into the extracellular environment as a $79 \mathrm{kDa}$ protein after cleavage of 25 residues in the Nterminal region (Han et al. 2002). The purified TLH had strong phospholipase activity on the egg yolk emulsion. It was reasoned that the TLH protein may well be a phospholipase just like the VHH hemolysin of $V$. harveyi (Zhong et al. 2006, Sun et al. 2007). Also, a GDSL lipase domain was found in the deduced amino acid sequence of TLH. It has been reported that some Vibrio hemolysins demonstrate phospholipase activity. For example, the lecithin-dependent hemolysin of $V$. parahaemolyticus has phospholipase $\mathrm{A}_{2} /$ lysophospholipase activity (Shinoda et al. 1991), and the hemolysin of $V$. cholerae O139 has phospholipase $\mathrm{C}$ activity (Pal et al. 1997). In addition, some Vibrio phospholipases show hemolytic activity on erythrocytes. For example, PhlA from V. mimicus demonstrated high hemolytic activity to rainbow trout and tilapia erythrocytes (Lee et al. 2002), and V. vulnificus extracellular phospholipase $\mathrm{A}_{2}$ and lysophospholipase had hemolytic activity to sheep and mouse erythrocytes (Testa et al. 1984). In our study, regarding the effect of metallic cations on hemolytic activity, a consistent change was detected using either the hemolytic microtiter or egg yolk plate method (data obtained using the second method were not shown). These data revealed a correlation between hemolysin and phospholipase.

The hemolytic activity of several Vibrio hemolysins has been well documented to be inhibited by divalent cations, such as $\mathrm{Ca}^{2+}, \mathrm{Mg}^{2+}$, and $\mathrm{Mn}^{2+}$ (Miyake et al. 1989, Zitzer et al. 1995, Miyoshi et al. 1997, Han et al. 2002). Miyoshi et al. (1997) reported that the hemolytic activity of $V$. mimicus hemolysin was inhibited by addi- tion of $<1 \mathrm{mM} \mathrm{Cu}^{2+}, \mathrm{Zn}^{2+}$, or $\mathrm{Ni}^{2+}$, and reasoned that these cations may function as osmotic protectants against the increase in intracellular osmotic pressure arising from blockage of influx of extracellular water via the toxin-induced pore at the cell membrane (Miyoshi et al. 1997). Hemolysins from V. metschnikovii, $V$. cholerae E1 Tor, and $V$. fluvialis were also influenced by divalent cations (Miyake et al. 1989, Zitzer et al. 1995, Han et al. 2002). Thus, it is relevant that the hemolytic activity of TLH was decreased to $50 \%$ by addition of all the divalent cations at $0.1 \mathrm{mM}$ concentration, i.e. $\mathrm{Mg}^{2+}$, $\mathrm{Ca}^{2+}, \mathrm{Mn}^{2+}, \mathrm{Co}^{2+}, \mathrm{Ni}^{2+}, \mathrm{Cu}^{2+}, \mathrm{Zn}^{2+}$, and $\mathrm{Ba}^{2+}$, and that the hemolytic activity was not affected by addition of monovalent cations $\left(\mathrm{Na}^{+}\right.$and $\mathrm{K}^{+}$). However, the mechanism by which these cations inhibit the hemolytic reaction is poorly understood. The hemolytic activity is possibly decreased by the potent oxidation of divalent cations, and the side-chain radical or the ionic environment of TLH may also take effect in the reaction.

Chemical modification of proteins is a convenient method for the investigation of the structure and function of enzymes and the composition of the enzyme active center (Zhou \& Wang 1988). Our results showed that TLH was sensitive to the modifications of the hydroxy group and the disulfide bond, and especially sensitive to the hydrosulfide modification. These results indicated that there might be a serine residue containing a hydroxy group within the active site of $\mathrm{TLH}$, and one or more disulfide bonds were necessary for the stable conformation. The hydrosulfide of cysteine might play an important role in the catalysis of TLH. Concurrently, the mutation of Ser153 on the conserved active Gly-Asp-Ser-Leu motif of VHH from Vibrio harveyi would result in the loss of all hemolytic activity (Sun et al. 2007).

TLH was lethal to zebrafish when injected intraperitoneally, and the $\mathrm{LD}_{50}$ value of $0.8 \mu \mathrm{g}$ protein $\mathrm{g}^{-1}$ fish was similar to that of VHH in flounder, i.e. $1.2 \mu \mathrm{g}$ protein $\mathrm{g}^{-1}$ fish (Zhong et al. 2006). Comparatively, the lethal toxicity test of TDH from Vibrio alginolyticus showed that $\mathrm{LD}_{50}$ values were 5.68 and $8.34 \mu \mathrm{g} \mathrm{TDH}$ $\mathrm{g}^{-1}$ body weight for mouse and crimson snapper, respectively (Cai et al. 2007). The present demonstration of the toxicity of TLH on fish will facilitate the identification of the virulence factor that could be used as a candidate antigen for vaccine development and as a diagnostic tool for vibriosis.

Acknowledgements. This work was supported by a grant from the National Natural Science Foundation of China (NSFC) and the Research Grants Council (RGC) of the Hong Kong Joint Research Scheme (No. 30831160512 from NSFC, and No. N_CUHK447/08 from RGC), a grant from the NSFC (No. 30771656), a key Project of Chinese Ministry of Education (No. 108082), and a grant from the Major State Basic Research Development Program of China (No. 2006CB101803). 


\section{LITERATURE CITED}

Austin B, Austin DA (1989) Methods for the microbiological examination of fish and shellfish. Ellis Horwood, Chichester

Bradford MM (1976) A rapid and sensitive method for the quantitation of microgram quantities of protein using the principle of protein-dye binding. Anal Biochem 72: 248-254

Cai SH, Wu ZH, Jian JC, Lu YS (2007) Cloning and expression of gene encoding the thermostable direct hemolysin from Vibrio alginolyticus strain HY9901, the causative agent of vibriosis of crimson snapper (Lutjanus erythopterus). J Appl Microbiol 103:289-296

Egidius E (1987) Vibriosis: pathogenicity and pathology. A review. Aquaculture 67:15-28

González-Escalona N, Blackstone GM, DePaola A (2006) Characterization of a Vibrio alginolyticus strain, isolated from Alaskan oysters, carrying a hemolysin gene similar to the thermostable direct hemolysin-related hemolysin gene (trh) of Vibrio parahaemolyticus. Appl Environ Microbiol 72:7925-7929

> Han JH, Lee JH, Choi YH, Park JH, Choi TJ, Kong IS (2002) Purification, characterization and molecular cloning of Vibrio fluvialis hemolysin. Biochim Biophys Acta 1599: 106-114

Jayaprakash NS, Pai SS, Philip R, Singh IS (2006) Isolation of a pathogenic strain of Vibrio alginolyticus from necrotic larvae of Macrobrachium rosenbergii (de Man). J Fish Dis 29:187-191

> Jeon JH, Kim JT, Kim YJ, Kim HK and others (2009) Cloning and characterization of a new cold-active lipase from a deep-sea sediment metagenome. Appl Microbiol Biotechnol 81:865-874

Kazan D, Erarslan A (2001) Identification of catalytically essential amino acid residues of penicillin $\mathrm{G}$ acylase obtained from a mutant of Escherichia coli ATCC 11105. Process Biochem 36:861-867

Kim NJ, Sugano Y, Hirai M, Shoda M (2000) Removal of a high load of ammonia gas by a marine bacterium, Vibrio alginolyticus. J Biosci Bioeng 90:410-415

Lee JH, Ahn SH, Kim SH, Choi YH, Park KJ, Kong IS (2002) Characterization of Vibrio mimicus phospholipase A (PhlA) and cytotoxicity on fish cell. Biochem Biophys Res Commun 298:269-276

Li J, Zhou LR, Woo NYS (2003) Invasion route and pathogenic mechanisms of Vibrio alginolyticus to silver sea bream Sparus sarba. J Aquat Anim Health 15:302-313

Miyake M, Honda T, Miwatani T (1989) Effects of divalent cations and saccharides on Vibrio metschnikovii cytolysininduced hemolysis of rabbit erythrocytes. Infect Immun 57:158-163

- Miyoshi S, Sasahara K, Akamatsu S, Rahman MM, Katsu T, Tomochika KI, Shinoda S (1997) Purification and characterization of a hemolysin produced by Vibrio mimicus. Infect Immun 65:1830-1835

> Montero AB, Austin B (1999) Characterization of extracellular products from an isolate of Vibrio harveyi recovered from diseased post-larval Penaeus vannamei (Bonne). J Fish Dis 22:377-386

Editorial responsibility: Catherine Collins, Aberdeen, UK
Nielsen H, Brunak S, von Heijne G (1999) Machine learning approaches for the prediction of signal peptides and other protein sorting signals. Protein Eng Des Sel 12:3-9

Pal S, Guhathakurta B, Sasmal D, Mallick R, Datta A (1997) Purification and characterization of a hemolysin with phospholipase C activity from Vibrio cholerae O139. FEMS Microbiol Lett 147:115-120

Parvathi A, George J, Kumar S (2009) Prevalence and heterogeneity of hemolysin gene vhh among hatchery isolates of Vibrio harveyi in India. Curr Microbiol 59:42-47

Selvin J, Lipton AP (2003) Vibrio alginolyticus associated with white spot disease of Penaeus monodon. Dis Aquat Org $57: 147-150$

> Shinoda S (1999) Protein toxins produced by pathogenic vibrios. J Nat Toxins 8:259-269

> Shinoda S, Matsuoka H, Tsuchie T, Miyoshi SI, Yamamoto S, Taniguchi H, Mizuguchi Y (1991) Purification and characterization of a lecithin-dependent hemolysin from Escherichia coli transformed by a Vibrio parahaemolyticus gene. J Gen Microbiol 137:2705-2711

Shirai A, Matsuyama A, Yashiroda Y, Hashimoto A and others (2008) Global analysis of gel mobility of proteins and its use in target identification. J Biol Chem 283:10745-10752

Singh V, Somvanshi P, Rathore G, Kapoor D, Mishra BN (2009) Gene cloning, expression and homology modeling of hemolysin gene from Aeromonas hydrophila. Protein Expr Purif 65:1-7

Sultan NAM, Kenoth R, Swamy MJ (2004) Purification, physicochemical characterization, saccharide specificity, and chemical modification of a Gal/GalNAc specific lectin from the seeds of Trichosanthes dioica. Arch Biochem Biophys 432:212-221

Sun B, Zhang XH, Tang X, Wang S, Zhong Y, Chen J, Austin $B$ (2007) A single residue change in Vibrio harveyi hemolysin results in the loss of phospholipase and hemolytic activities and pathogenicity for turbot (Scophthalmus maximus). J Bacteriol 189:2575-2579

> Testa J, Daniel LW, Kreger AS (1984) Extracellular phospholipase A2 and lysophospholipase produced by Vibrio vulnificus. Infect Immun 45:458-463

Wang SX, Zhang XH, Zhong YB, Sun BG, Chen JX (2007) Genes encoding the Vibrio harveyi haemolysin (VHH)/ thermolabile haemolysin (TLH) are widespread in Vibrios. Acta Microbiol Sin 47:874-881

Wardlaw AC (1985) Practical statistics for experimental biologists. John Wiley \& Sons, Chichester

Zhang XH, Austin B (2005) Haemolysins in Vibrio species. J Appl Microbiol 98:1011-1019

Zhang XH, Meaden PG, Austin B (2001) Duplication of hemolysin genes in a virulent isolate of Vibrio harveyi. Appl Environ Microbiol 67:3161-3167

> Zhong Y, Zhang XH, Chen J, Chi Z, Sun B, Li Y, Austin B (2006) Overexpression, purification, characterization and pathogenitiy of Vibrio harveyi haemolysin VHH. Infect Immun 74:6001-6005

Zhou H, Wang H (1988) Chemical modification of proteins. Tsinghua University Press, Beijing

Zitzer AI, Palmer WM, Bhakdi S (1995) Characterization of Vibrio cholera El Tor cytolysin as an oligomerizing poreforming toxin. Med Microbiol Immunol 184:37-44

Submitted: December 14, 2009; Accepted: March 31, 2010

Proofs received from author(s): June 1, 2010 